\title{
New challenges for the clinical and translational imaging journal
}

\author{
Orazio Schillaci $^{1}$
}

Published online: 12 August 2020

(C) Italian Association of Nuclear Medicine and Molecular Imaging 2020

Dear Readers, Authors, Reviewers, members of the editorial board, and all who gave their support to the journal,

We inform you that Clinical and Translational Imaging is now moving to new challenges. From 2013 to date, the journal has continuously improved and increased in visibility, downloads, quality, and citations. However, the success of a journal depends on a lot of conditions, first of all the worldwide collaboration! From 2013 to today, the journal has more and more taken a specific direction, by including many type of manuscripts and by covering different topic in nuclear medicine and molecular imaging.

However, due to the recent sad news about the founder of the Clinical and Translational Imaging Prof. Giovanni Lucignani [1], the Italian Association of Nuclear Medicine (AIMN) has decided to actively support the journal, by calling for a new Editor-in-Chief. The person identified for this assignment is Dr. Laura Evangelista. She has been always actively involved in the AIMN and also in other international collaborations. We strongly believe that she will be able to continue the excellent work made by Prof. Lucignani, thus favoring the constantly growing of the Journal.

Moreover, we are happy to announce that the Clinical and Translational Imaging has receive its first impact factor. The impact factor 2019 is 2506 , found on rank 58 out of 133 in the category "Radiology, Nuclear Medicine and Medical Imaging". This achievement represents the first milestone that everybody who is involved in the Journal has contributed to achieve.
Finally, we would invite to continue to support the journal, because the dissemination of the scientific evidences in nuclear medicine and molecular imaging can be useful for the management of patients and for the growth of the discipline.

Orazio Schillaci

President of the Italian Association of Nuclear Medicine (AIMN)

\section{Compliance with ethical standards}

Conflict of interest The author declares that there is no conflict of interest.

\section{Reference}

1. Italian Association of Nuclear Medicine (AIMN) (2020) In memoriam of Professor Giovanni Lucignani. Clin Transl Imaging 8:227-228. https://doi.org/10.1007/s40336-020-00369-x

Publisher's Note Springer Nature remains neutral with regard to jurisdictional claims in published maps and institutional affiliations.
Please do also note the editorial "We will continue to grow up together!" from "Laura Evangelista, Editor-in-Chief, Clinical and Translational Imaging, https://doi.org/10.1007/s40336-020-00382 -0 .

Orazio Schillaci

orazio.schillaci@uniroma2.it

1 Nuclear Medicine Unit, Department of Biomedicine and Prevention, University of Tor Vergata, Rome, Italy 